\title{
Produção e aceitabilidade de cenoura sob cultivo orgânico no inverno e no verão
}

\author{
Dalva Paulus*; Cláudia de A Moura; Anderson Santin; Ana Regina Dalhem; Gilmar A Nava; Celso EP \\ Ramos
}

UTFPR, C. postal 157, 85660-000 Dois Vizinhos-PR; dalvaufsmdeutch@yahoo.com.br (*autor para correspondência); claudiaamkuhn@ yahoo.com.br; santin8@hotmail.com; reginautfpr@yahoo.com.br; gilmarnava@utfpr.edu.br; celedura@utfpr.edu.br

\section{RESUMO}

Para o cultivo da cenoura é importante conhecer a adaptação das cultivares de acordo com as condições climáticas do local e a preferência do consumidor. Com o objetivo de avaliar o desempenho e a aceitação, detectando assim a preferência dos consumidores a diferentes cultivares de cenoura em sistema de cultivo orgânico, realizou-se o presente trabalho. Avaliou-se o desempenho das cultivares de cenoura em Dois Vizinhos (PR). O delineamento experimental utilizado foi blocos casualizados com cinco repetições e quatro tratamentos para a época de inverno (cvs Nantes, Shin Kuroda, Danvers e Flaker) e cinco tratamentos para o verão (cvs Shin Kuroda, Kuronan, Brasília, Esplanada e Carandaí). Avaliou-se a resistência à queima das folhas (Alternaria dauci), incidência de ombro verde, sólidos solúveis totais, produtividade e aceitabilidade, por meio de análise sensorial das cenouras in natura e em conserva tipo picles. Para o cultivo de inverno a cultivar Nantes resultou em maior produtividade $(29,02 \mathrm{t}$ $\mathrm{ha}^{-1}$ ) e para o cultivo de verão a produtividade da cultivar Esplanada foi superior $\left(32,0 t \mathrm{tha}^{-1}\right)$ às demais cultivares, que não diferiram estatisticamente entre si. A cv. Esplanada apresentou maior resistência à queima das folhas e menor percentagem $(5,6 \%)$ de ombro verde. As características organolépticas das cultivares apresentaram boa aceitabilidade pelos consumidores participantes.

Palavras-chave: Daucus carota, cultivares, aceitação, análise sensorial.

\begin{abstract}
Production and acceptability of carrot under organic cultivation in winter and summer

For the carrot cultivation it is important to understand the adaptation of cultivars according to the local weather conditions and consumer preference. The objective was to evaluate the performance and acceptance, thereby detecting the consumer's preference for different carrot cultivars in organic cropping system. The performance of the cultivars Nantes, Shin Kuroda and Danvers Flaker was evaluated in the winter season and cultivars Shin Kuroda, Kuronan, Brasilia, Esplanada and Carandaí for cultivation of summer in Dois Vizinhos, Paraná state, Brazil. The experimental design was randomized blocks with five replications and four treatments for the winter season and five treatments for the summer season. We analyzed the resistance to leaf blight (Alternaria dauci), incidence of green shoulder, total soluble solids, yield and acceptability through sensory analysis of fresh carrots and canned pickles type. On the winter crop, cultivar Nantes resulted in higher yield (29.02 $\left.\mathrm{t} \mathrm{ha}^{-1}\right)$ and on the summer crop cultivar Esplanada productivity was higher $\left(32.0 \mathrm{tha}^{-1}\right)$ without statistical difference. The cv. Esplanada was more resistant to leaf blight and presented the lowest percentage $(5.6 \%)$ of green shoulder. For sensory analysis, the cvs presented good acceptability from the participating consumers.
\end{abstract}

Keywords: Daucus carota, cultivars, acceptance.

\section{(Recebido para publicação em 13 de junho de 2011; aceito em 12 de julho de 2012) (Received on June 13, 2011; accepted on July 12, 2012)}

A cenoura (Daucus carota) é uma hortaliça de grande importância econômica no Brasil. Pode ser plantada durante todo ano, desde que a cv. seja adequada à época de plantio (Luz et al., 2009). No Brasil, em 2009, a produtividade da cenoura foi de 29,93 t ha-1 e com produção de 784 mil toneladas (EMBRAPA, 2011). O estado do Paraná é o terceiro produtor nacional, com aproximadamente 6.206 ha plantados (2008/09) e produtividade média de 29,49 t ha-1. A produção da olerácea no estado é da ordem de 230 mil toneladas por ano (CEPEA, 2008). A cenoura apresenta alto conteúdo de vitamina $A$, textura macia e paladar agradável (Filgueira, 2008). Caracteres relacionados com o aspecto visual das raízes, como formato, lisura, coloração laranja intensa externa e internamente, sem pigmentos verdes ou roxos na parte superior (ombro), com comprimento e diâmetro variando entre 15 e $20 \mathrm{~cm}$ e 3 e $4 \mathrm{~cm}$, respectivamente, para consumo in natura (Vieira \& Pessoa, 1997) são os principais determinantes da qualidade no mercado brasileiro, durante o processo de comercialização (Lana \& Vieira, 2000).

A preocupação com a saúde e a procura por alimentos mais saudáveis é uma tendência mundial. São várias as vantagens, citadas na literatura, do sistema orgânico de produção sobre a qualidade dos alimentos. Segundo
Machado \& Corazza (2004), hortaliças orgânicas não contém resíduos químicos de agrotóxicos, como aquelas produzidas em sistema convencional. Estudos indicam que existem diferenças relativas à qualidade, quando são considerados atributos como sabor e valor nutricional, mediante comparação entre os alimentos produzidos orgânica e convencionalmente (Favaro-Trindade et al., 2007). Em estudos realizados com cenoura em sistema orgânico, durante dez anos, Souza (1996) observou que a produtividade foi $7 \%$ superior em relação ao sistema convencional. Segundo o autor, devido à falta de informações sobre cultivares para sistemas alternativos de produção, os produtores utilizam cultivares de 
cenoura desenvolvidas para o sistema convencional.

Para o cultivo da cenoura é importante conhecer a adaptação das cultivares de acordo com as condições climáticas do local. As cultivares recomendadas para o cultivo de inverno são as do grupo Nantes, sendo esses materiais exigentes em clima ameno, intolerantes à temperatura e pluviosidade elevadas, condições sob as quais apresentam alta suscetibilidade à queima das folhas. As cultivares recomendadas para o cultivo de verão pertencem ao grupo Brasília (Brasília, Carandaí, Alvorada e Esplanada) que apresentam adaptação à temperatura e pluviosidade elevadas, e alta resistência à queima-das-folhas (Filgueira, 2008). Em avaliações realizadas com a cv. Esplanada na região do Distrito Federal, produtores orgânicos chegaram a alcançar uma média de $28 \mathrm{t} \mathrm{ha}^{-1}$ (Vieira et al., 2005). Luz et al., (2009) verificaram que no cultivo de verão, as cultivares Alvorada, Brasília Calibrada, Brasília Alta Seleção e Brasília RL apresentaram vantagens em produtividade total frente às cvs Carandaí, Forto e Nantes.

Uma das tendências da olericultura é atender as aceitações e preferências do consumidor em termos de aparência, sabor e cor de hortaliças. Nesse sentido, a análise sensorial é utilizada para medir, analisar e interpretar reações das características dos alimentos pelo consumidor em potencial (Ferreira, 1999). Resultados de análise sensorial realizada com genótipos de cenoura em sistema orgânico e convencional por Carvalho et al. (2005), mostraram que amostras de cenoura provenientes do sistema orgânico foram preferidas pelos consumidores.

A cenoura está entre as principais hortaliças cultivadas em sistema orgânico de produção, porém são escassas as informações sobre o desempenho das cultivares e a avaliação sensorial nesse sistema de plantio. Com este trabalho tivemos como objetivo avaliar o desempenho agronômico, aceitabilidade e a preferência dos consumidores por cultivares de cenoura em sistema de cultivo orgânico.

\section{MATERIAL E MÉTODOS}

Os experimentos foram conduzidos em duas épocas, sendo o primeiro no outono-inverno, no período de maio a setembro de 2008, e o segundo no verão, no período de novembro de 2009 a fevereiro de 2010, na área experimental da horta orgânica, localizada na Universidade Tecnológica Federal do Paraná em

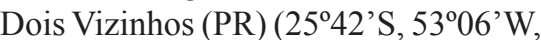
altitude $520 \mathrm{~m}$ ) (INMET, 2010). O clima da região é classificado como $\mathrm{Cfa}$ subtropical úmido, sem estação seca definida e temperatura média do mês mais quente de $22^{\circ} \mathrm{C}$. O solo local é do tipo Nitossolo vermelho distroférrico (Bhering et al., 2008). As características químicas do solo na camada $0-15 \mathrm{~cm}$ foram: $\mathrm{pH} \mathrm{CaCl}=6,00$, M.O. $=38,87 \mathrm{~g}$ $\mathrm{dm}^{-3}, \mathrm{P}=86,42 \mathrm{mg} \mathrm{dm}^{-3}, \mathrm{~K}=1,40 \mathrm{cmol}$ $\mathrm{dm}^{-3}, \mathrm{Ca}=8,73 \mathrm{cmol}_{\mathrm{c}} \mathrm{dm}^{-3}, \mathrm{Mg}=4,15$ $\mathrm{cmol}_{\mathrm{c}} \mathrm{dm}^{-3}, \mathrm{Al}=0,0 \mathrm{cmol}_{\mathrm{c}} \mathrm{dm}^{-3}$ e $\mathrm{V}=$ $78,25 \%$.

O delineamento experimental utilizado foi blocos casualizados com cinco repetições e quatro tratamentos para a época de inverno e cinco tratamentos para a época de verão. As cultivares de cenoura utilizadas para o cultivo de inverno foram: Nantes, Shin Kuroda, Danvers e Flaker e para o cultivo de verão: Shin Kuroda, Kuronan, Brasília, Esplanada e Carandaí, recomendadas para as épocas de inverno e verão, respectivamente (Penteado, 2007). A unidade experimental foi constituída por canteiro com 1,20 m de largura, 20 $\mathrm{cm}$ de altura e $3 \mathrm{~m}$ de comprimento. A semeadura foi realizada em sulcos espaçados em $20 \mathrm{~cm}$ entre fileiras e 0,5 $\mathrm{cm}$ de profundidade. Cada canteiro foi constituído de quatro linhas de semeadura. A área útil foi de $2,40 \mathrm{~m}^{2}$ e bordadura de $1,20 \mathrm{~m}^{2}$. O desbaste foi realizado 30 dias após a emergência, deixando-se 5 cm entre plantas.

A área utilizada para a instalação do experimento foi preparada com enxada rotativa à profundidade de $20 \mathrm{~cm}$. Foram fornecidos $3 \mathrm{~kg} \mathrm{~m}^{-2}$ de cama de aviário compostada. Para o preparo do composto, a cama de aviário foi colocada em leira, onde realizou-se revolvimento para permitir aeração e controle de temperatura; esta ficou curtindo durante três meses (Kiehl, 2004). A irrigação foi realizada conforme a necessidade da cultura, utilizando o sistema de irrigação por aspersão. Para controle de plantas espontâneas, procedeu-se a capina manual. Não foi aplicado nenhum tipo de controle de pragas e doenças.

Avaliou-se em todas as parcelas aos 35,50 e 75, e aos 35; 50;65; 80 e 95 dias após a semeadura, nos cultivos de verão e outono-inverno, respectivamente, a severidade da queima das folhas (Alternaria dauci) (Oliveira Filho et al., 1990).

As colheitas foram realizadas de forma manual aos 118 dias após a semeadura para o experimento de outono-inverno e aos 85 dias após a semeadura no período de verão. As avaliações foram realizadas nas duas linhas centrais na dimensão de $2 \mathrm{~m}$. O restante do canteiro foi considerado como bordadura. As raízes foram separadas das folhas, lavadas e deixadas à sombra para eliminação do excesso de umidade.

Foram avaliados o comprimento médio das raízes $(\mathrm{cm})$, diâmetro médio das raízes $(\mathrm{cm})$, altura $(\mathrm{cm})$ (distância entre o ápice da folha e a base do colo da raiz), produtividade ( $\left.\mathrm{t} \mathrm{ha}^{-1}\right)$, raízes com presença de ombro verde (\%). Para a obtenção do comprimento médio das raízes foram coletadas, aleatoriamente quinze cenouras de cada parcela, sendo cada uma delas medida com paquímetro digital do ápice, na inserção da coroa foliar, até a base (Luz et al, 2009).

O teor de sólidos solúveis totais foi determinado por refratometria, homogeneizando-se a amostra em liquidificador doméstico e transferindo duas gotas para o prisma do refratômetro. Os resultados foram expressos em ${ }^{\circ}$ Brix.

Realizaram-se em duas etapas as análises sensoriais: in natura e em conserva tipo picles de cenoura foram realizadas em laboratório sensorial montado, localizado na Universidade Tecnológica Federal do Paraná. Os provadores para ambas análises sensoriais foram convidados de forma aleatória, abrangendo professores, funcionários e estudantes do local. As cultivares utilizadas foram higienizadas com hipoclorito a $1 \%$ e posteriormente, cortadas de forma padronizada para o teste de aceitabilidade da cenoura in natura.

Para preparação de picles realizou-se a higienização das cenouras, cortes longitudinais no formato de bastão em torno de $10 \mathrm{~cm}$ por $1 \mathrm{~cm}$ de espessura, em 
seqüência passou-se pelo processo de branqueamento e drenagem. A salmoura foi preparada na seguinte composição: $40 \%$ de ácido acético $\left(\mathrm{CH}_{3} \mathrm{COOH}\right)$ e $60 \%$ de água, adição de $3 \%$ de $\mathrm{NaCl}$ e $0,5 \%$ de sacarose $\left(\mathrm{C}_{12} \mathrm{H}_{22} \mathrm{O}_{11}\right)$ (Benevides \& Fortunato, 1998).

Para o teste de aceitabilidade in natura e em conserva tipo picles, os provadores receberam amostras de cada cultivar, cortadas em cubos uniformes e uma ficha para representar a escala hedônica estruturada mista de nove pontos $(9=$ gostei extremamente, $8=$ gostei muito, $7=$ gostei moderadamente, $6=$ gostei ligeiramente, $5=$ indiferente, $4=$ desgostei ligeiramente, $3=$ desgostei, $2=$ desgostei muito, 1 = desgostei extremamente) para as variáveis sabor, textura (crocância), aparência, cor e impressão global de cada amostra (Carpenter et al., 2000). Os participantes da análise sensorial assinaram um termo de aceitação de participação, de acordo com o código de ética e pesquisa como estabelece a Resolução $n^{\circ} 196$, de 10 de outubro de 1996, do Conselho Nacional de Saúde. Participaram do teste de preferência in natura e em conserva tipo picles, 59 provadores.

Foi realizada a análise de variância e as médias comparadas pelo teste de Tukey a $5 \%$ de probabilidade (SAS, 1999).

\section{RESULTADOS E DISCUSSÃO}

\section{Cultivo de inverno}

Com relação ao comprimento, as raízes são classificadas em três grupos: curtas (10-11,99 cm), médias (12-16,99 $\mathrm{cm})$ e longas $(17-20 \mathrm{~cm}$ ) (Freire et al., 1984). No cultivo de inverno, observou-se que a cultivar Nantes apresentou o maior comprimento com $16,3 \mathrm{~cm}$. Para o diâmetro e altura a Danvers foi superior, apresentando 3,0 e $56,9 \mathrm{~cm}$, respectivamente. Desta forma, as raízes das cultivares em estudo foram classificadas como médias, o que atende a preferência do consumidor brasileiro (Lana \& Vieira, 2000). Essas características também foram verificadas por Siqueira et al. (2005) que, em avaliações de raízes de cultivares de cenoura em sistema de produção orgânica, obtiveram raízes médias $(12-17 \mathrm{~cm})$ e diâmetro de 2,5-3,0 cm.

A produtividade da cultivar Nantes foi significativamente superior $(29,02$ $t$ ha $^{-1}$ ) em relação às demais cultivares avaliadas, que não diferiram significativamente entre si (Tabela 1). Esses rendimentos estão na média dos rendimentos de 29,5 tha-1 do estado do Paraná (CEPEA, 2008) e da média nacional $(29,93 \mathrm{t}$ ha $^{-1}$ ). Luz et al. (2009), nas condições de Minas Gerais, em sistema convencional, obtiveram produtividade de $30,70 \mathrm{tha}^{-1}$ no período de outono-inverno.

A cv. Nantes é recomendada para o cultivo de inverno (Filgueira, 2008). Pelos resultados obtidos percebe-se que a mesma apresentou raízes de qualidade e adaptação às condições climáticas de temperaturas médias máximas e mínimas de 17 e $15^{\circ} \mathrm{C}$, respectivamente, as quais corresponderam às faixas de temperatura de 10 e $25^{\circ} \mathrm{C}$ citadas por Rubatzky et al. (1999), como sendo propícias para obtenção de raízes de cenoura com melhor qualidade.

Não foram encontradas nas cultivares de inverno raízes com ombro verde (Tabela 1). Esse distúrbio fisiológico ocorre com maior freqüência no verão, em plantas com reduzida massa foliar $\mathrm{e}$ também a incidência depende da característica genética da cultivar (Finger et al., 2005). Luz et al. (2009) também não encontraram incidência desta anomalia na cv. Nantes, o que condiz com a afirmação da mesma ser considerada padrão de qualidade no Brasil (Souza, 1994), e que esta cultivar possui baixa incidência de ombro verde (Finger et al., 2005).

Com relação à severidade de queima das folhas não foram encontradas diferenças estatísticas entre as cultivares (Tabela 1). Lesões entre 61-100\% na maior parte das folhas superiores e todas as inferiores mortas são considerados percentuais altos de severidade (Oliveira

Tabela 1. Comprimento (COM), diâmetro (DIA), altura (ALT), produtividade (PROD), porcentagem de severidade de queima das folhas (PSQF), ombro verde (OV) e sólidos solúveis totais (SST) de cultivares de cenoura nos cultivos de inverno e de verão em sistema de cultivo orgânico (length, diameter, height, yield and percentage of leaf blight severity, green shoulder and total soluble solids of carrot cultivars, planted in winter and summer in the organic cropping system). Dois Vizinhos, UTFPR, 2010.

\begin{tabular}{|c|c|c|c|c|c|c|c|}
\hline Cultivo de inverno & COM (cm) & DIA (cm) & ALT (cm) & PROD (t ha-1) & PSQF (\%) & OV (\%) & SST ( ${ }^{\circ}$ Brix) \\
\hline Danvers & $12,3 b^{*}$ & $3,0 \mathrm{a}$ & $56,9 \mathrm{a}$ & $22,03 b$ & $21,4 a^{*}$ & 0 & $9,0 \mathrm{a}$ \\
\hline Shin Kuroda & $12,5 b$ & $2,2 b$ & $49,6 b$ & $23,03 b$ & $17,2 \mathrm{a}$ & 0 & $9,5 \mathrm{a}$ \\
\hline Nantes & $16,3 \mathrm{a}$ & $2,4 b$ & $51,2 \mathrm{~b}$ & $29,02 \mathrm{a}$ & $26,3 a$ & 0 & $7,0 \mathrm{~b}$ \\
\hline Flaker & $12,6 \mathrm{~b}$ & $2,2 b$ & $41,4 \mathrm{c}$ & $19,73 b$ & $14,5 \mathrm{a}$ & 0 & $6,5 \mathrm{~b}$ \\
\hline CV (\%) & 28 & 23 & 14 & 25 & 18 & - & 12 \\
\hline \multicolumn{8}{|l|}{ Cultivo de verão } \\
\hline Shin Kuroda & $14,7 \mathrm{~b}$ & $3,00 \mathrm{a}$ & $57,50 \mathrm{a}$ & $17,1 b$ & $28 a^{*}$ & $25,3 \mathrm{a}$ & $7,7 \mathrm{~b}$ \\
\hline Kuronan & $14,8 \mathrm{~b}$ & $3,26 \mathrm{a}$ & $52,96 \mathrm{~b}$ & $18,3 b$ & $32 \mathrm{a}$ & $26,7 \mathrm{a}$ & $10,0 \mathrm{a}$ \\
\hline Brasíllia & $15,9 \mathrm{~b}$ & $3,21 \mathrm{a}$ & $41,97 \mathrm{c}$ & $20,0 \mathrm{~b}$ & $31 \mathrm{a}$ & $27,0 \mathrm{a}$ & $7,3 b$ \\
\hline Esplanada & $18,0 \mathrm{a}$ & $2,56 b$ & $39,86 \mathrm{c}$ & $32,0 \mathrm{a}$ & $22 b$ & $5,6 \mathrm{c}$ & $7,1 b$ \\
\hline Carandaí & $15,3 \mathrm{~b}$ & $3,04 \mathrm{a}$ & $49,35 \mathrm{~b}$ & $18,4 \mathrm{~b}$ & $35 \mathrm{a}$ & $13,0 \mathrm{~b}$ & $6,8 \mathrm{~b}$ \\
\hline CV (\%) & 6 & 9 & 11 & 13 & 18 & 24 & 9 \\
\hline
\end{tabular}

*Médias seguidas da mesma letra não diferem entre si pelo teste de Tukey a 5\% (means followed by same letter did not differ from each other, Tukey's test, $\mathrm{p}<0.05)$. 
Tabela 2. Teste de aceitação para os atributos aparência (AP), cor (C), textura (TEX), sabor (S) e impressão global (IG) aplicando escala hedônica* para as amostras in natura de cenoura no cultivo de inverno e verão em sistema de produção orgânico (test of acceptance, appearance, color, texture, flavor and overall impression applying hedonic scale for samples of fresh carrots in the winter season and summer in the organic production system). Dois Vizinhos, UTFPR, 2010.

\begin{tabular}{lccccc}
\hline Cultivo de inverno & AP & C & TEX & S & IG \\
\hline Danvers & $7,00 \mathrm{a}^{* *}$ & $7,34 \mathrm{a}$ & $7,17 \mathrm{a}$ & $7,29 \mathrm{a}$ & $7,34 \mathrm{a}$ \\
Shin Kuroda & $6,50 \mathrm{a}$ & $7,54 \mathrm{a}$ & $6,77 \mathrm{a}$ & $7,00 \mathrm{a}$ & $6,83 \mathrm{~b}$ \\
Nantes & $6,80 \mathrm{a}$ & $6,06 \mathrm{~b}$ & $6,94 \mathrm{a}$ & $6,46 \mathrm{~b}$ & $6,80 \mathrm{~b}$ \\
Flaker & $6,54 \mathrm{a}$ & $7,20 \mathrm{a}$ & $6,54 \mathrm{a}$ & $6,09 \mathrm{~b}$ & $6,49 \mathrm{~b}$ \\
\hline CV $(\%)$ & 24 & 21 & 22 & 26 & 21 \\
\hline Cultivo de verão & & & & & $6,10 \mathrm{a}$ \\
\hline Shin Kuroda & $6,42 \mathrm{a}^{*}$ & $6,58 \mathrm{~b}$ & $6,64 \mathrm{a}$ & $6,45 \mathrm{a}$ & $6,15 \mathrm{a}$ \\
Kuronan & $6,48 \mathrm{a}$ & $7,46 \mathrm{a}$ & $6,55 \mathrm{a}$ & $6,48 \mathrm{a}$ & $6,48 \mathrm{a}$ \\
Brasília & $6,58 \mathrm{a}$ & $6,71 \mathrm{~b}$ & $6,97 \mathrm{a}$ & $6,68 \mathrm{a}$ & $6,25 \mathrm{a}$ \\
Esplanada & $6,55 \mathrm{a}$ & $6,58 \mathrm{~b}$ & $6,52 \mathrm{a}$ & $6,48 \mathrm{a}$ & $6,77 \mathrm{a}$ \\
Carandaí & $6,13 \mathrm{a}$ & $6,03 \mathrm{~b}$ & $6,55 \mathrm{a}$ & $6,19 \mathrm{a}$ & 19 \\
\hline CV $(\%)$ & 26 & 20 & 23 & 6 & 17 \\
\hline
\end{tabular}

*Escala hedônica estruturada mista de nove pontos $(9=$ gostei extremamente, $8=$ gostei muito, $7=$ gostei moderadamente, $6=$ gostei ligeiramente, $5=$ indiferente, $4=$ desgostei ligeiramente, $3=$ desgostei, $2=$ desgostei muito, $1=$ desgostei extremamente) (hedonic scale of nine grades $(9=$ liked extremely, $8=$ liked very much, $7=$ liked moderately, $6=$ liked slightly, $5=$ indifferent, $4=$ disliked slightly, $3=$ disliked, 2 = disliked very much, 1 = disliked extremely) (Carpenter et al., 2000); **Médias seguidas da mesma letra não diferem entre si pelo teste de Tukey a 5\% (means followed by same letter did not differ from each other, Tukey's test, $\mathrm{p}<0.05$ ).

Tabela 3. Teste de aceitação para os atributos aparência (AP), cor (C), textura (TEX), sabor (S) e impressão global (IG) aplicando escala hedônica* para as amostras de picles de cultivares de cenoura no cultivo de inverno e verão em sistema de produção orgânico (test of acceptance, appearance, color, texture, flavor and overall impression applying hedonic scale for samples of fresh carrots in the winter season and summer in the organic production system). Dois Vizinhos, UTFPR, 2010.

\begin{tabular}{lccccc}
\hline Cultivo de inverno & AP & C & TEX & S & IG \\
\hline Danvers & $6,60 \mathrm{~b}^{* *}$ & $6,88 \mathrm{c}$ & $6,65 \mathrm{a}$ & $5,92 \mathrm{~b}$ & $6,58 \mathrm{c}$ \\
Shin Kuroda & $7,54 \mathrm{a}$ & $7,96 \mathrm{a}$ & $7,38 \mathrm{a}$ & $7,04 \mathrm{a}$ & $7,46 \mathrm{a}$ \\
Nantes & $6,50 \mathrm{~b}$ & $6,23 \mathrm{c}$ & $6,65 \mathrm{a}$ & $6,19 \mathrm{~b}$ & $6,15 \mathrm{c}$ \\
Flaker & $7,62 \mathrm{a}$ & $7,69 \mathrm{~b}$ & $7,04 \mathrm{a}$ & $7,11 \mathrm{a}$ & $7,15 \mathrm{~b}$ \\
\hline CV (\%) & 21 & 22 & 21 & 23 & 20 \\
\hline Cultivo de verão & & & & $6,52 \mathrm{a}$ & $7,05 \mathrm{a}$ \\
\hline Schin Kuroda & $7,23 \mathrm{a}^{*}$ & $7,42 \mathrm{a}$ & $6,78 \mathrm{a}$ & $6,39 \mathrm{a}$ & $6,76 \mathrm{a}$ \\
Kuronan & $7,29 \mathrm{a}$ & $7,13 \mathrm{a}$ & $6,46 \mathrm{a}$ & $6,69 \mathrm{a}$ & $6,91 \mathrm{a}$ \\
Brasília & $7,12 \mathrm{a}$ & $7,05 \mathrm{a}$ & $6,63 \mathrm{a}$ & $6,58 \mathrm{a}$ \\
Esplanada & $7,25 \mathrm{a}$ & $7,30 \mathrm{a}$ & $6,49 \mathrm{a}$ & $6,05 \mathrm{a}$ & $6,91 \mathrm{a}$ \\
Carandaí & $7,32 \mathrm{a}$ & $7,52 \mathrm{a}$ & $6,56 \mathrm{a}$ & $5,97 \mathrm{a}$ & 16 \\
\hline CV (\%) & 15 & 16 & 22 & 24 & 6 \\
\hline
\end{tabular}

*Escala hedônica estruturada mista de nove pontos $(9=$ gostei extremamente, $8=$ gostei muito, $7=$ gostei moderadamente, $6=$ gostei ligeiramente, $5=$ indiferente, $4=$ desgostei ligeiramente, $3=$ desgostei, $2=$ desgostei muito, $1=$ desgostei extremamente) (hedonic scale of nine grades $(9=$ liked extremely, $8=$ liked very much, $7=$ liked moderately, $6=$ liked slightly, $5=$ indifferent, $4=$ disliked slightly, $3=$ disliked, 2 = disliked very much, 1 = disliked extremely) (Carpenter et al., 2000); **Médias seguidas da mesma letra não diferem entre si pelo teste de Tukey a 5\% (means followed by same letter did not differ from each other, Tukey's test, $\mathrm{p}<0.05$ ).

Filho, 1990). Os baixos percentuais de severidade das cultivares Shin Kuroda, Kuronan e Brasília (25,3, 26,7 e 27\%), respectivamente, encontrados nas cultivares de inverno devem-se ao fato de que as condições climáticas não foram favoráveis ao desenvolvimento da doen- ça. Segundo Muniz \& Magalhães (1984) para o desenvolvimento de Alternaria dauci, os requisitos básicos são alta umidade relativa do ar, alta precipitação e temperatura moderada. A temperatura média foi de $16,4^{\circ} \mathrm{C}$, a precipitação total durante o período de condução do ex- perimento foi de $662 \mathrm{~mm}$ e a umidade relativa do ar média de $73 \%$.

Os resultados dos sólidos solúveis totais demonstraram que as cultivares Danvers e Shin Kuroda apresentaram os maiores valores, com 9,0 e 9,5 ${ }^{\circ}$ Brix, respectivamente. As demais não dife- 
riram estatisticamente entre si (Tabela 1). Os valores de sólidos solúveis totais obtidos no presente trabalho estão acima da faixa de 6,5 a $7,5^{\circ}$ Brix, recomendada para colheita e consumo citada por Barros Júnior et al. (2005), o que permite afirmar que a cenoura estava com grau de doçura adequado para o consumo (Chitarra \& Chitarra, 2000).

O conteúdo de sólidos solúveis totais obtidos no presente estudo pode estar relacionado ao sistema de cultivo orgânico associado às características genéticas da cultivar. Segundo Chitarra \& Carvalho (1984) os sólidos solúveis totais são influenciados pelas condições de cultivo (sistema de produção, tipo de solo, clima) e por fatores genéticos. Confirmando os resultados obtidos, Alasalvar et al. (2001) e Rosenfeld et al. (1997) também constataram a influência do genótipo no conteúdo de sólidos solúveis totais de cenoura. Incrementar o grau de doçura do produto deverá ser uma característica importante no estabelecimento de objetivos de melhoramento, uma vez que a doçura é um atributo desejável no aumento da qualidade de cenouras (Alasalvar et al., 2001).

A análise sensorial in natura das cultivares de cenoura de inverno mostrou que para o atributo cor as cultivares Danvers, Shin Kuroda e Flaker receberam as melhores notas, 7,34, 7,54 e 7,20 , respectivamente. Para o atributo sabor as melhores notas foram para as cultivares Danvers e Shin Kuroda e para a impressão global, a cultivar Danvers recebeu nota superior $(7,34)$ em relação às demais. Para aparência e textura os tratamentos não diferiram estatisticamente (Tabela 2).

Analisando as notas designadas pelos provadores nos atributos da análise sensorial das cultivares de cenoura in natura, observou-se que as cultivares Danvers e Shin Kuroda tiveram maior aceitação pelos provadores. Observou-se que as cultivares Shin Kuroda e Danvers, que apresentaram maior grau de doçura, com maiores valores de sólidos solúveis, também foram às preferidas pelos provadores para o atributo sabor, o que contribuiu para maior aceitação dessas cultivares.

Também, verificou-se que o corte em cubos manteve o sabor e textura dessas cultivares. Esses resultados estão de acordo com a avaliação de qualidade sensorial da cenoura minimamente processada, onde foi observado que o tipo de corte em rodelas mantém o sabor e textura, quando comparado ao corte ralado, o que poder ter contribuído para os resultados de aceitação (Resende et al., 2003).

Para a análise sensorial da cenoura em conserva tipo picles verificou-se que as melhores notas para o atributo aparência foram para as cultivares Shin Kuroda e Flaker (Tabela 3). Para os atributos cor e impressão global a cultivar Shin Kuroda foi a que resultou em maior aceitação pelos provadores, recebendo as melhores notas 7,96 e 7,46, atribuída entre os conceitos gostei muito a gostei moderadamente, respectivamente. Assim como na análise sensorial in natura, também para a cenoura em conserva tipo picles, a cultivar Shin Kuroda foi a que obteve melhor aceitação pelos provadores.

\section{Cultivo de Verão}

No cultivo de verão, verificou-se que a cultivar Esplanada apresentou maior comprimento de raiz $(18 \mathrm{~cm})$; as demais cultivares não diferiram estatisticamente entre si. Para a variável diâmetro, a mesma apresentou o menor valor $(2,56$ $\mathrm{cm}$ ), as demais não diferiram estatisticamente entre si. A cultivar Shin Kuroda resultou em maior altura em relação às demais cultivares avaliadas (Tabela 1). As raízes da cultivar Esplanada foram classificadas como longas, enquanto que as raízes das demais cultivares foram classificadas como médias, estando de acordo com os padrões de qualidade do mercado brasileiro (Lana \& Vieira, 2000).

A produtividade $\left(32,0 \mathrm{t} \mathrm{ha}^{-1}\right) \mathrm{da} \mathrm{cv}$. Esplanada foi superior às demais cultivares, que não diferiram estatisticamente entre si (Tabela 1). Os resultados de produtividade da Esplanada podem ser explicados pelo seu potencial genético de rendimento citado por Vieira et al. (2005). Produção esta semelhante à verificada por Steiner et al. (2009) em sistema orgânico, na região de Marechal Cândido Rondon (PR), que obteve 27,8 $\mathrm{t} \mathrm{ha}^{-1}$. Em avaliações realizadas com a cultivar Esplanada no Distrito Federal, produtores orgânicos chegaram a alcançar média de 28 t ha ${ }^{-1}$ (Vieira et al., 2005).

Os resultados de produção da cv. Esplanada também podem ser explicados pelas condições climáticas (temperatura média de $24^{\circ} \mathrm{C}$, mínima média de $23^{\circ} \mathrm{C}$, máxima média de $25^{\circ} \mathrm{C}$ e precipitação total de $724 \mathrm{~mm}$ ) favoráveis à taxa de crescimento das raízes e da parte aérea e obtenção de raízes com melhor qualidade (alongadas e baixo percentual de ombro verde) (Rubatzky et al., 1999). As faixas de temperatura obtidas durante o período de condução do estudo estão de acordo com as citadas por Finger et al. (2005) como ideais para o cultivo de cenoura no período de verão.

A cv. Esplanada foi menos afetada com a severidade da queima das folhas. A cultivar Carandaí foi a que apresentou a maior severidade (35\%), mas sem diferir estatisticamente das cultivares Shin Kuroda, Kuronan e Brasília (Tabela 1). $\mathrm{O}$ baixo valor de severidade encontrado no cultivo de verão, possivelmente deve-se ao fato de que as condições climáticas não foram favoráveis ao desenvolvimento da doença. Esta menor severidade da cv. Esplanada, aliada as condições climáticas favoráveis e ao potencial genético da cv contribuíram para maior produtividade.

Os resultados obtidos neste trabalho estão de acordo com as informações de Vieira et al. (2005). De acordo com esses autores, a cultivar Esplanada apresenta alta resistência à queima-das-folhas, produz raízes de formato cilíndrico, alongadas e finas, com aproximadamente $20 \mathrm{~cm}$ de comprimento e $3 \mathrm{~cm}$ de diâmetro; baixa incidência de ombro verde, em relação às cultivares do grupo Brasília.

Com relação ao ombro verde, a cv. Esplanada apresentou a menor percentagem (5,6\%), seguida da cv. Carandaí. Por outro lado, as cultivares Shin Kuroda, Kuronan e Brasília apresentaram os maiores valores $(25,3,26,7$ e $27,0 \%$ ), respectivamente, entretanto, sem diferirem estatisticamente entre si (Tabela 1).

Além da predisposição genética, também verificou-se que durante o cultivo de verão, as condições de temperatura foram mais elevadas em relação ao cultivo de inverno, o que resultou em 
plantas com reduzida massa foliar, o que pode ter contribuído para os maiores valores de ombro verde nas cultivares Shin Kuroda, Kuronan e Brasília. Valores ainda maiores de ombro verde foram obtidos nas cultivares Brasília Calibrada (33,2\%), Brasília RL (30,7\%) por Luz et al. (2000) nas condições de Uberlância (MG), com pluviosidade de $1.172 \mathrm{~mm}$ e temperatura média de $23,7^{\circ} \mathrm{C}$ e máxima de $27,7^{\circ} \mathrm{C}$.

Os resultados obtidos com as cultivares em estudo confirmam as recomendações de Filgueira (2008), ou seja, cultivares recomendadas para o cultivo de verão (Brasília, Carandaí, Alvorada e Esplanada) apresentam adaptação à temperatura e pluviosidade elevadas, e alta resistência à queima-das-folhas.

Os resultados de sólidos solúveis totais variaram de 6,8 a $10{ }^{\circ}$ Brix. Verificou-se diferença significativa entre as cultivares avaliadas, sendo que a cv. Kuronan apresentou o maior valor de açúcares (10 ${ }^{\circ}$ Brix), as demais não diferiram entre si (Tabela 1). Os resultados de sólidos solúveis totais da cv. Kuronan mostraram que a mesma, no momento da colheita, estava com teor de açúcares acima das demais, o que pode ser explicado, em função das características genéticas da cultivar associada às condições climáticas favoráveis, com temperatura média de $24^{\circ} \mathrm{C}$ e radiação solar de $913 \mathrm{Kj} \mathrm{m}^{-2}$, condições essas favoráveis ao acúmulo de açúcares e de acordo com as faixas ideais de cultivo citadas por Finger et al. (2005).

A análise sensorial in natura das cultivares de verão mostrou que para os atributos aparência, textura, sabor e impressão global não houve diferença significativa entre os parâmetros avaliados. Para o atributo cor, a cultivar Kuronan recebeu a melhor nota $(7,46)$ em relação às demais (Tabela 2 ).

Verificou-se que, nas cultivares de cenoura servidas in natura, os provadores tiveram dificuldade em diferenciar os genótipos por atributos como textura e sabor. Segundo Sant'ana (1995) cenouras servidas cruas influenciam na preferência dos provadores, devido à presença de substâncias voláteis indesejáveis que dificultam a diferenciação de cultivares, por características sensoriais. Segundo o autor, a cenoura preparada a vapor ou na forma de conserva, pode eliminar essas substâncias, acentuando o sabor e facilitando a preferência do provador.

As notas atribuídas pelos provadores para as amostras de cenoura in natura corresponderam na escala hedônica de gostei moderadamente a gostei ligeiramente das cultivares de cenoura, o que condiz com boa aceitação pelos provadores. Um dos fatores que pode ter contribuído para aceitabilidade das cultivares de cenoura foi a concentração de açucares que está diretamente relacionada com o sabor.

O resultado obtido da análise sensorial in natura da cultivar Kuronan possivelmente, se deve pelo fato dessa cultivar apresentar maior concentração de açúcares (10 ${ }^{\circ}$ Brix), coloração laranja avermelhada e maciez (Penteado, 2007), o que pode ter influenciado a preferência dos provadores com relação ao atributo cor.

$\mathrm{O}$ sistema de cultivo associado às condições climáticas favoráveis contribuiu para a obtenção de cenouras com qualidade visual adequada, boa aceitabilidade e preferência do consumidor. Características semelhantes de aceitabilidade e preferência também foram observadas por Evers (1989) em sistema orgânico de produção.

Em conserva tipo picles as cultivares de cenoura não diferiram estatisticamente entre si (Tabela 3). Para os atributos cor e sabor as respostas dos provadores corresponderam ao conceito na escala hedônica de gostei moderadamente e gostei ligeiramente, respectivamente. Observou-se que as cultivares de cenoura em conserva tipo picles apresentaram boa aceitação pelos provadores, podendo assim, ser feito a conserva para aproveitamento em excedente de safra, agregando valor ao produto final.

Conclui-se que no cultivo de inverno a cultivar Nantes resultou em maior produtividade. Com relação ao cultivo de verão, a cultivar Esplanada se destacou em produtividade, resistência à queima das folhas e ombro verde. Com relação à análise sensorial in natura e conserva tipo picles as características organolépticas das cultivares apresentaram boa aceitabilidade pelos consumidores.

\section{REFERÊNCIAS}

ALASALVAR C; GRIGOR JM; ZHANG D; QUANTICK PC; SHAHIDI F. 2001. Comparison of volatiles, phenolics, sugars, antioxidant vitamins and sensory quality of different collored carrot varieties. Journal of Agriculture and Food Chemistry 49: 14101416.

BARROS JÚNIOR AP; BEZZERA NETO F; SILVA EO; NEGREIROS MZ; OLIVEIRA EQ; SILVEIRA M; LIMA JSS; FREITAS KKC. 2005. Qualidade de raízes de cenoura em sistemas consorciados com alface sob diferentes densidades populacionais. Horticultura Brasileira 23: 290-293.

BENEVIDES CMJ; FORTUNATO DMN. 1998. Hortaliças Acidificadas. Ciência e Tecnologia de Alimentos 18: 12-21.

BHERING SB; SANTOS HG; BOGNOLA IA; CÚRCIO GR.; MANZATTO CV; CARVALHO JUNIOR W; CHAGAS CS; ÁGLIO MLD; SOUZA JS. 2008. Mapa de solos do Estado do Paraná: legenda atualizada. Rio de Janeiro: EMBRAPA/ IAPAR. 2008. 74p.

CARPENTER RP; LYON DH; HASDELL TA.2000. Análisis sensorial en el desarrollo y control de la calidad de alimentos. Zaragoza, España. 2000.191p.

CARVALHO AM; JUNQUEIRA AMR; VIEIRA JV; BOTELHO R. 2005. Análise sensorial de genótipos de cenoura cultivados em sistema orgânico e convencional. Horticultura Brasileira 23: 805-809.

CEPEA. 2008. Cenoura: Menor produtividade no inicio da safra de inverno valoriza a cenoura. Hortifruti Brasil 75: 26-27.

CHITARRA MIF; CARVALHO VD. 1984. Cenoura: qualidade e industrialização. Informe Agropecuário 10: p. 73-75.

CHITARRA MIF; CHITARRA AB.2000. Póscolheita de frutos e hortaliças: fisiologia e manuseio. Lavras: Fundação de Apoio ao Ensino, Pesquisa e Extensão. 293p.

EMBRAPA, Centro Nacional de Pesquisa de Hortaliças, Gama, DF. 2011. Disponível em: http://www.cnph.embrapa.br/paginas/ hortalicas_em_numeros/hortalicas_em numeros.htm. Acesso em: 20 de março de 2011

EVERS AM. 1989. The role of fertilization practices in the yield and quality of carrot (Daucus carota L.). Journal of Agricultural Science in Finland 61: 329-360.

FAVARO-TRINDADE CS; MARTELLO LS; MARCATTI B; MORETTI TS; PETRUS RR; ALMEIRDA E; FERRAZ JBS. 2007. Efeito dos Sistemas de Cultivo Orgânico, Hidropônico e Convencional na Qualidade de Alface Lisa. Brazilian Journal Food Technology 10: p.111-115.

FERREIRA VLP. 1999. Análise sensorial: testes discriminativos e afetivos. São Paulo: PROFÍQUA; CAMPINAS; SBCTA. 109 p.

FILGUEIRA FAR. 2008. Novo manual de 
olericultura: agrotecnologia moderna na produção e comercialização de hortaliças. 3 ed. Viçosa: UFV. 412p.

FINGER FL; DIAS DCFS; PUIATTI M. 2005. Cultura da cenoura. In: FONTES PCR (ed). Olericultura teoria e prática. Viçosa: Departamento de Fitotecnia/Setor de Olericultura. p. 371-384.

FREIRE FB; VIEIRA GS; DUARTE RMM. 1984. Colheita, classificação e embalagem de cenoura e mandioquinha salsa. Informe Agropecuário 10: 57-59.

INMET: Estação meteorológica A843 de Dois Vizinhos, PR. Disponível em: http://www. inmet.gov.br/sonabra/sonabra.html. Acesso em: 30 de Novembro de 2010.

KIEHL EJ. Manual de compostagen: maturação e qualidade do composto. 2004. Piracicaba: ESALQ. 173p.

LANA MM; VIEIRA J V. 2000. Fisiologia e manuseio pós-colheita de cenoura. EMBRAPA CNPH, Circular Técnica 21: 15.

LUZ JMQ; SILVA JÚNIOR JA; TEIXEIRA MSSC; SILVA MAD; SEVERINO GM; MELO B. 2009. Desempenho de cultivares de cenoura no verão e outono-inverno em Uberlândia-MG. Horticultura Brasileira 27: 096-099.

MACHADO F; CORAZZA R. 2004. Desafios tecnológicos, organizacionais e financeiros da agricultura orgânica no Brasil. Revista de la Facultad de Ecominía 26: 21-40. MUNIZ JOL; MAGALHÃES CA. 1984. A resistência de cultivares de cenoura (Daucus carota L.) à queima das folhas em Guarapiranga-CE. Fortaleza: Empresa de Pesquisa Agropecuária do Ceará, 12p. (Boletim de pesquisa/EPACE, 4).

OLIVEIRA FILHO GM; JULIATTI FC; KERR WE. 1990. Uberlândia: nova cultivar de cenoura resistente a Alternaria dauci. Fitopatologia Brasileira 15: 150.

PENTEADO SR. 2007. Cultivo de Hortaliças Ecológicas. Campinas: SP. 253p.

RESENDE JM; COELHO SFA; CASTRO EC; JÚNIOR OJS; NASCIMENTO T; BENEDETTI BC. 2003. Avaliação sensorial de cenoura minimamente processada em diferentes cortes. Horticultura Brasileira 21: 381.

RUBATZKY VE; QUIROS CF; SIMON PW. 1999. Carrots and related vegetables Umbelliferae. CABI Publishing: Oxon. 304p.

ROSENFELD HJ; BAARDSETH P; SKREDE G. 1997. Evaluation of carrots varieties for production of deep-fried carrot chips - IV. The influence of growing environment on carrot raw material. Food Research International.30: p. 611-618.

SANT'ANA HMP. Efeito do método de preparo sobre a estabilidade de carotenóides em cenoura (Daucus carota L.). 1995. Viçosa:
Universidade Federal de Viçosa. 115p. (Tese mestrado).

SAS INSTITUTE. 1999. SAS: user's guide statistics: version 8.0 edition. Cary. 956 p.

SIQUEIRA RG; BARRELLA TP; SANTOS RHS; MEDEIROS EAA; SIMÕES AN; MOREIRA SI; PUSCHMANN R; MAPELI NC. 2005. Avaliação de cultivares de cenoura em sistema de produção orgânica. Horticultura brasileira 23: 5-8.

SOUZA JL. 1996. Efeito do composto orgânico e da cobertura morta na cultura da cenoura. In: CONGRESSO BRASILEIRO DE OLERICULTURA, 36. Resumos... Rio de Janeiro: SOB (CD-ROM).

STEINER F; ECHER MM; LEITE ACC. 2009. Características produtivas de cenoura "Esplanada" em função do modo de aplicação de composto orgânico e utilização de cobertura morta. Cultivando o Saber 2: 46-52

VIEIRA JV; PESSOA HBSV. 1997. Cultivo da cenoura (Daucus carota L.). Brasília: Embrapa Hortaliças, 19p. (Embrapa Hortaliças. Instrução Técnica, 13).

VIEIRA JV; SILVA JBC; CHARCHAR JM; RESENDE FV; FONSECA MEN; CARVALHO AM; MACHADO CMM. 2005. Esplanada: cultivar de cenoura de verão para fins de processamento. Horticultura Brasileira 23: 851-852. 